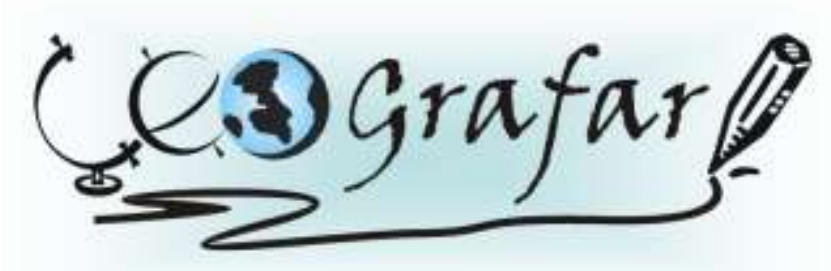

Revista Eletrônica do Programa de Pós-Graduaçāo em Geografla - UFPR

\title{
FATORES MOTIVACIONAIS À VISITAÇÃO DE ÁREAS VERDES- ESTUDO DE CASO: JARDIM BOTÂNICO DE CURITIBA, PARANÁ, BRASIL
}

\author{
RAQUEL RIBEIRO DE SOUZA SILVA ${ }^{1}$ \\ DANIELA BIONDI ${ }^{2}$
}

\begin{abstract}
RESUMO
A análise das motivações dos indivíduos constitui-se em uma importante ferramenta para avaliação e aprimoramento da experiência turística. O objetivo geral desta pesquisa foi verificar a motivação de visita no atrativo mais visitado da cidade de Curitiba, o Jardim Botânico, considerando o perfil motivacional de seus usuários e a possível relação com as estações do ano. Os métodos utilizados foram aplicação de questionário in loco composto por perguntas relacionadas à idade, ao gênero, ao nível de escolaridade, a região geográfica de procedência e se o motivo de visita ao atrativo era a prática de turismo, lazer, pesquisa ou outros não listados no questionário. A aplicação aconteceu durante duas semanas nos meses de maio, julho, outubro e dezembro de 2011, sendo que cada um destes meses representaram uma estação do ano. As coletas foram assim distribuídas com intuito de verificar se há significativas alterações no perfil motivacional da demanda entre uma estação e outra. $O$ resultado encontrado foi que as características predominantes dos usuários do Jardim Botânico de Curitiba encontradas nesta pesquisa foram: gênero feminino; faixa etária de 19 a 30 anos; nível médio de escolaridade; origem geográfica de outro estado; e motivação de viagem o lazer. Independentemente das estações do ano a origem geográfica dos usuários da área de estudo, foi o fator determinante para estabelecer o lazer como principal motivador de visitação, pois os residentes da cidade de Curitiba são os que mais utilizam o Jardim Botânico, com finalidade de lazer, enquanto que os usuários do atrativo provenientes de outros estados e cidades brasileiras e outros países afirmaram ser o turismo a motivação da visita.
\end{abstract}

Palavras - chaves: Turismo. Motivação. Atrativo turístico.

\footnotetext{
${ }^{1}$ Bacharel em Turismo. Mestre em Engenharia Florestal - Universidade Federal do Paraná; unesp2004@yahoo.com.br

2 Engenheira Florestal. Profa ${ }_{2}$. Dr ${ }^{\text {a }}$ Depto. de Ciências Florestais - Universidade Federal do Paraná; dbiondi@ufpr.br
} 


\title{
GREEN AREAS MOTIVATIONAL FACTORS TO VISITATION - CASE STUDY: BOTANICAL GARDEN OF CURITIBA, PARANA, BRAZIL
}

\begin{abstract}
The analysis of the motivations of individuals constitutes an important tool for evaluating and improvement of the tourist experience. The objective of this research was to find what is the motivation to visit the most visited attraction in the city of Curitiba, the Botanical Garden, considering the motivational profile of its users and the possible relationship with the years seasons. The methods used were the application of a survey in situ composed of questions relating to age, gender, education level, geographic region of origin and if the reason to visit the attraction was the practice of tourism, leisure, research or other not listed in the survey. The application took place during two weeks in May, July, October and December 2011, each one of these months represented one year season. The surveys were distributed in order to verify if there are significant changes in the motivational profile of demand from one season to another. The result found was that the predominant features of the users of the Botanical Garden of Curitiba were: female gender, age range 19-30 years, average educational level, geographical origin from another state and leisure as travel motivation. Regardless of the seasons the geographical origin of users of the study area, was the determining factor for establishing recreation as the main motivator for visitors, as the residents of the city of Curitiba are the ones who use the Botanical Garden, with the purpose of leisure, while users of the attraction from other Brazilian states and other countries claimed to be tourism the motivation for the visit.
\end{abstract}

Keywords: Tourism. Motivation. Tourism attraction.

\section{INTRODUÇÃO}

Observa-se com frequência modificações na paisagem dos espaços urbanos, ora pelas construções de empreendimentos comerciais e residenciais, ora pela disseminação de favelas e ocupações irregulares para construção de moradias, fazendo com que as áreas verdes cedam lugar ao concreto.

Segundo Lima et al. (1994) as áreas verdes são espaços com predomínio de vegetação arbórea que englobam praças, jardins públicos, parques urbanos, canteiros centrais de avenidas, trevos, rotatórias e calçadas.

Hardt (2000) assinala duas categorias de áreas verdes: pública e privada, onde na primeira estão incluídas as seguintes tipologias: parques, praças e unidades de conservação. E na segunda categoria encontram-se as tipologias jardins e quintais. 
Além das funções ecológica-ambiental, estética e de lazer, recentemente as áreas verdes tanto públicas como privadas nos centros urbanos possuem uma propensão a serem ou se transformarem em atrativos turísticos. Os parques, bosques e jardins públicos de Curitiba são exemplos clássicos desta realidade, sendo estes os principais atrativos da Linha Turismo (URBS, 2012).

Beni (2004, p. 311), inclui os jardins e hortos botânicos na lista de categorização de atrativos turísticos, e a definição para ambos os espaços é concebida por como sendo "instituições destinadas à conservação e multiplicação de espécimes vegetais, visando sua preservação e a visitação pública".

A visitação a estes espaços pode ser realizada tanto por moradores do entorno como por turistas, pois na concepção de Beni (2004, p. 335) os jardins são equipamentos turísticos, que contam com "áreas destinadas ao lazer com tratamento paisagístico".

Assim, o tratamento paisagístico dispensado aos jardins botânicos do século XXI traz consigo, além das funções ecológicas, um importante papel no embelezamento da cidade e se traduzem em espaços de relaxamento para 0 estresse diário que acompanha a vida citadina, por meio da contemplação da paisagem e, em escala menor, ao propiciar contato com elementos naturais, sobretudo com a vegetação (SEGAWA, 1996).

Os jardins e hortos botânicos figuram também na lista de categorização de atrativos turísticos. A definição para ambos os espaços é concebida por Beni (2004, p. 311), como sendo "instituições destinadas à conservação e multiplicação de espécimes vegetais, visando sua preservação e a visitação pública".

Segundo Beni (2004, p. 335), a visitação a estes espaços pode ser realizada tanto por moradores do entorno como por turistas, pois os jardins são equipamentos turísticos, que contam com "áreas destinadas ao lazer com tratamento paisagístico".

O artigo $1^{\circ}$ da resolução 266 do Conselho Nacional do Meio Ambiente (CONAMA) define o termo jardim botânico e lista seus objetivos (BRASIL, 2000):

área protegida, constituída, no seu todo ou em parte, por coleções de plantas vivas cientificamente reconhecidas, organizadas, documentadas e identificadas, com a finalidade de estudo, pesquisa e documentação do patrimônio florístico do país, acessível ao público, no todo ou em parte, servindo à educação, à cultura, ao lazer e à conservação do meio ambiente. 
A Constituição Federal de 1988, em seu artigo 225 (BRASIL, 1988), está indiretamente relacionada aos Jardins Botânicos, pois em linhas gerais assegura que todo cidadão tem o direito a um meio ambiente ecologicamente bem equilibrado e de uso comum de todos.

Da mesma forma, a Lei 6938/1981 que instituiu a Política Nacional do Meio Ambiente (BRASIL, 1981) e a Lei 9985/2000 que institui o Sistema Nacional de Unidade de Conservação (BRASIL, 2000) estão indiretamente relacionadas aos jardins botânicos, considerando os objetivos de conservação destas áreas.

A resolução 266 de 03/08/2000 do Conselho Nacional do Meio Ambiente (CONAMA) está diretamente relacionada aos jardins botânicos, pois estabelece diretrizes para a criação e normativa o funcionamento destes jardins. Além disso, cria a comissão nacional de jardins botânicos, com a finalidade de assessorar a secretaria executiva do CONAMA no acompanhamento e análise de assuntos concernentes a estas áreas (BRASIL, 2000).

Complementando a resolução 266, em 2001 foi estabelecida a resolução 287 (BRASIL, 2001), a qual delegou ao Instituto de Pesquisa Jardim Botânico do Rio de Janeiro (JBRJ) as competências do Ministério do Meio Ambiente relativas ao registro de novos jardins botânicos e institui o registro e enquadramento provisórios.

Todos estes regulamentos são importantes para assegurar 0 desenvolvimento e fortalecimento institucional dos jardins botânicos brasileiros, evitando assim que estas áreas desapareçam e se transformem em parque público (REUNIÃO DOS JARDINS BOTÂNICOS, 2002).

Atualmente no Brasil, existem 34 jardins botânicos, localizados em 17 estados da federação, concentrados na região Sudeste, sendo que o estado de São Paulo abriga o maior número deles (PEREIRA; COSTA, 2010).

No Estado do Paraná, a cidade de Curitiba destaca-se por possuir 23.164.533 $\mathrm{m}^{2}$ de seu território municipal ocupado por 1053 áreas verdes (IPPUC, 2011).

Dentre todas estas áreas verdes, conforme dados da Secretaria de Estado do Turismo, no ano de 2007, o Jardim Botânico posicionou-se em primeiro lugar no ranking dos atrativos turísticos mais citados pelos entrevistados daquele ano (IPPUC, 2007). Em 2009, segundo dados do Instituto Municipal de Turismo, o 
Jardim Botânico manteve-se em primeiro lugar entre os atrativos turísticos mais visitados pelos entrevistados (CURITIBA, 2009).

Frente à relevância destes dados de visitação, esta pesquisa tem como objetivo analisar e pontuar os fatores que motivam a visitação a este atrativo turístico, Jardim Botânico de Curitiba - PR.

\section{MATERIAL E MÉTODOS}

\subsection{JARDIM BOTÂNICO DE CURITIBA}

O objeto de estudo localiza-se na cidade de Curitiba, capital do Estado do Paraná, no bairro Jardim Botânico, entre a Avenida Lothário Meissner e a Rua Ostoja Roguski, conforme ilustra a figura 1. O atrativo dispõe de uma área de 17,8 ha, a qual está situada nas coordenadas geográficas: $25^{\circ} 26^{\prime} \mathrm{S}$ e $49^{\circ} 14^{\prime} \mathrm{W}$ (RBJB, 2004).

\section{FIGURA 1 - LOCALIZAÇÃO DO JARDIM BOTÂNICO DE CURITIBA-PR}

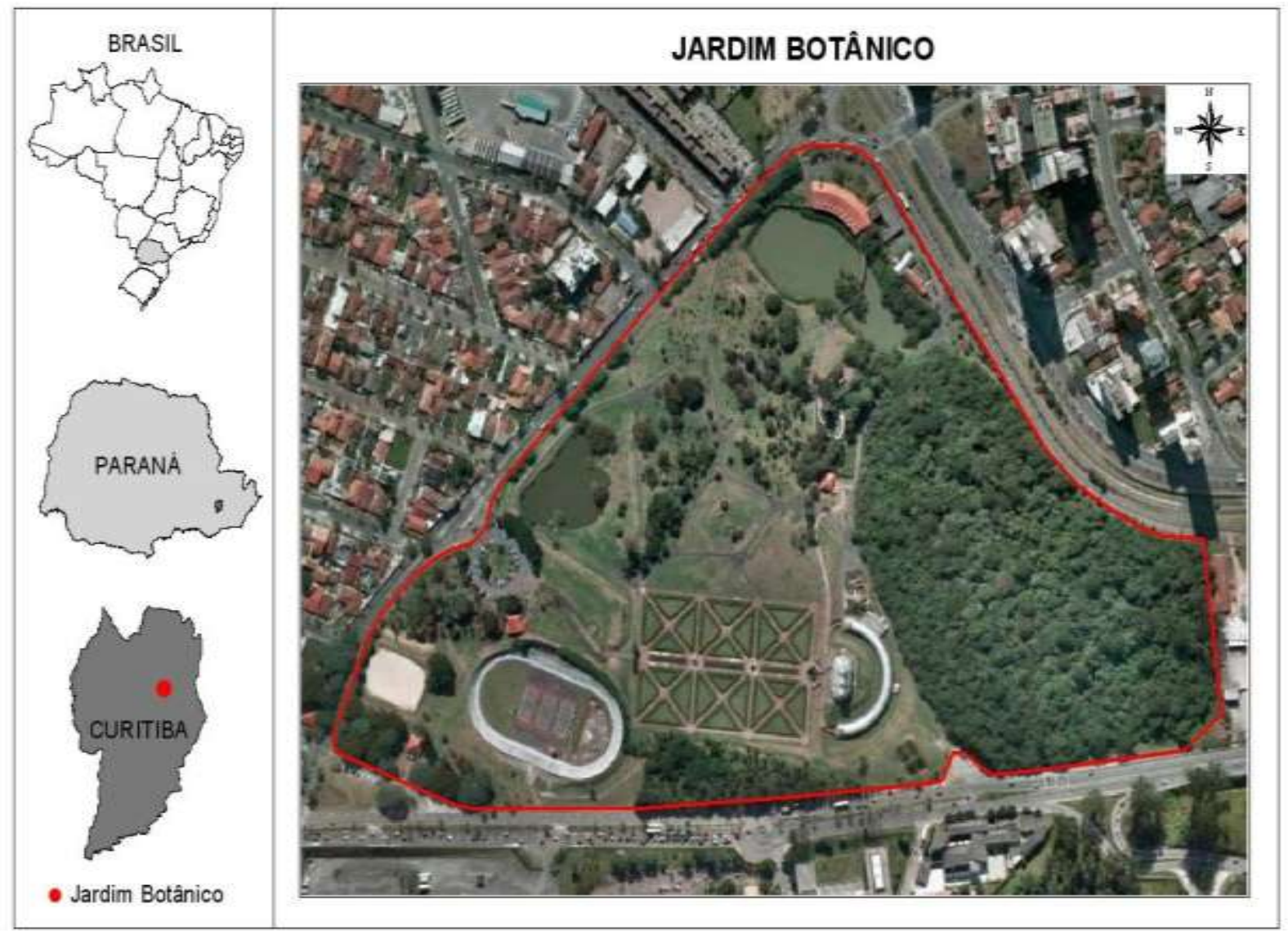

FONTE: Google Earth (2009). ELABORAÇÃO: A Autora (2011). 
Geograficamente a cidade de Curitiba está situada num altiplano de 934 metros acima do nível do mar e possui um relevo ondulado. A área total do município é de 430,9 km², onde se distribuem 1.828.092 habitantes (IPPUC, 2010).

O município possui um clima subtropical, nas classificações e derivações de Köppen (MAACK, 1981), o qual caracteriza este tipo clima pela ausência de estação seca, presença de verões frescos e invernos com geadas frequentes e ocasional precipitação de neve.

\subsection{EQUIPAMENTOS E SERVIÇOS NO JARDIM BOTÂNICO DE CURITIBA}

A principal atração turística e equipamento presente no Jardim Botânico de Curitiba é a estufa de ferro e vidro, dividida em dois andares, onde estão as coleções de plantas características de regiões tropicais, entre elas espécies representativas da Mata Atlântica sob condições de umidade e temperatura controladas.

No andar elevado da estufa é possível ter uma visão panorâmica do jardim, podendo ser vistos exemplares de espécies como palmito, embaúba, brinco-deprincesa, guapuruvu, epífitas entre outros (RBJB, 2004).

Inspirada no Palácio de Cristal de Londres, esta estufa, é circundada pelo jardim francês com canteiros geométricos, e é um dos principais atrativos turísticos da cidade (IPPUC, 2007).

Outro equipamento incorporado ao Jardim Botânico de Curitiba em 1992 é o Museu Botânico Municipal, entretanto, sua fundação se deu em 1965, a partir da doação do acervo particular do botânico Gerdt Hatschbach. Este acervo possui um rico material de pesquisa, dentre eles o herbário, com cerca de 300 mil exsicatas e a biblioteca especifica de botânica com mais de 10 mil publicações de consulta local (RBJB, 2004).

Há ainda, um espaço para exposição de obras artísticas, tais como pintura e escultura, apresentando temas diversos durante o ano, como exemplo Orquídeas, Bonsai, Ikebanas, llustrações Botânicas, entre outros (RBJB, 2004).

Dentre os elementos destacados, os lagos, a estufa, as fontes, as trilhas, e o jardim francês são aqueles que mais agregam valor paisagístico ao local. 
Silva (2012) avaliando os equipamentos e serviços turísticos do Jardim Botânico de Curitiba constatou que os usuários apontam aspectos que precisam ser melhorados pela gestão local, tais como: ampliação da área de alimentação, aumento da quantidade de bebedouros e banheiros, elaboração de materiais informativos sobre os atrativos, guias internos e sinalização bilíngue.

No geral, os equipamentos e serviços que oferecem suporte aos usuários e visitantes do atrativo estão ilustrados na figura 3.

\section{FIGURA 3 - EQUIPAMENTOS E SERVIÇOS JARDIM BOTÂNICO DE CURITIBA (J.B.C)}

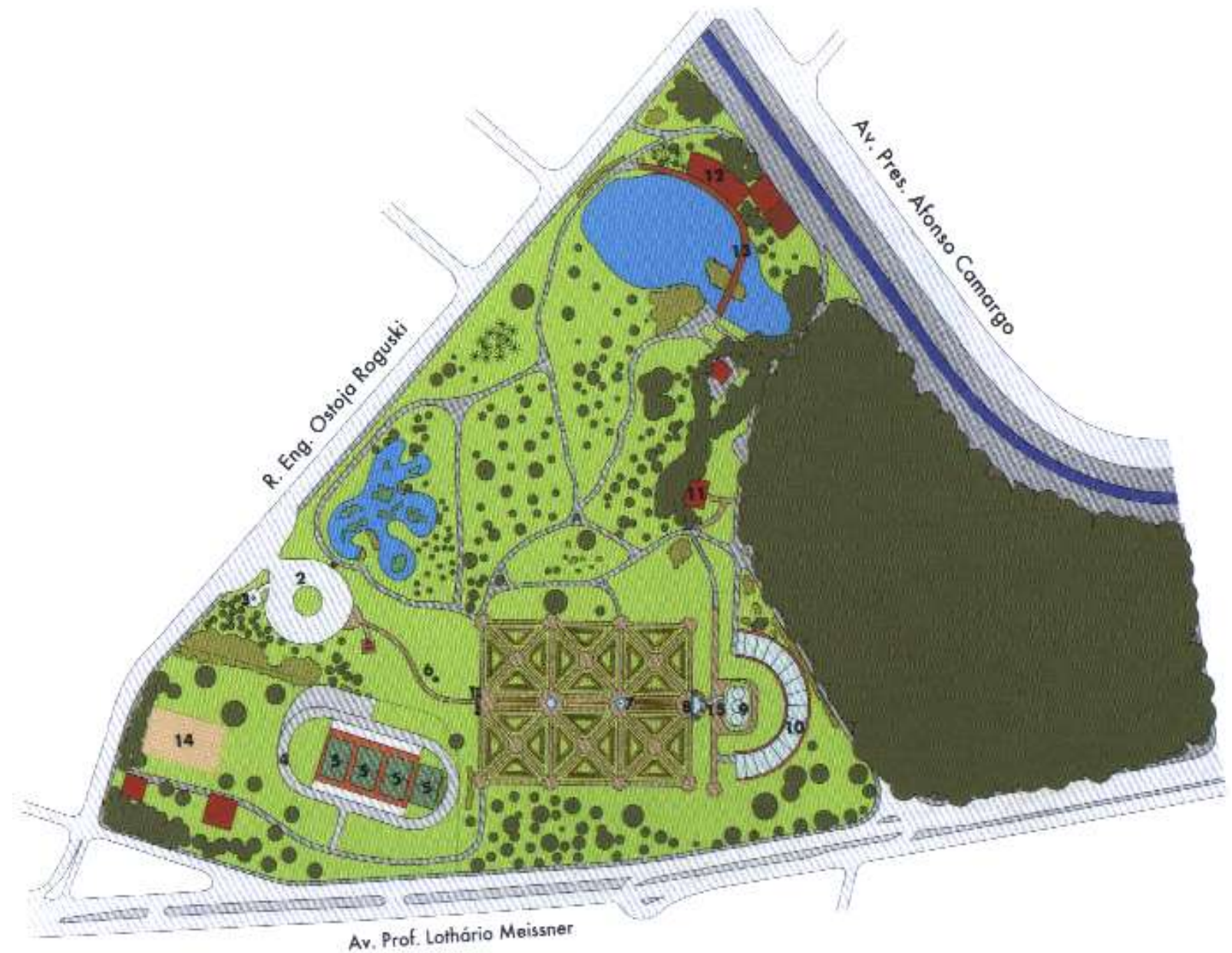

Nota: 1 - pórtico; 2 - estacionamento; 3 - estacionamento de motos; 4 - velódromo; 5 - quadras esportivas; 6 - tóten; 7 - chafariz ; 8 - cascata; 9 - estufa; 10 - área de exposições; 11 - sanitários; 12 - museu botânico; 13 - ponte; 14 - campo de futebol; 15 - espelho d'agua. FONTE: Macedo e Sakato (2010). 


\subsection{PROCEDIMENTO METODOLÓGICO}

Com o intuito de conhecer a motivação de visita ao Jardim Botânico de Curitiba foi realizada coletas de dados in loco por meio de aplicação de questionário (APÊNDICE 1) composto por perguntas relacionadas à idade, ao gênero, ao nível de escolaridade, a região geográfica de procedência e se o motivo de visita ao atrativo era a prática de turismo, lazer, pesquisa ou outros não listados no questionário.

Os questionários foram aplicados durante duas semanas nos meses de maio, julho, outubro e dezembro de 2011, sendo que cada um destes meses representaram uma estação do ano. As coletas foram assim distribuídas com intuito de verificar se há significativas alterações no perfil motivacional da demanda entre uma estação e outra.

Nesta pesquisa optou-se por nomear os entrevistados de usuários e não visitantes ou turistas, devido à diversidade de público que utiliza o local em estudo, os quais vão além destas duas categorias distintas, conforme observado em campo.

A compilação e tabulação dos dados coletados foram realizadas no programa Windows Excel 97-2003.

\section{RESULTADOS E DISCUSSÕES}

\subsection{PERFIL GERAL DOS USUÁRIOS DO JARDIM BOTÂNICO DE CURITIBA}

Os resultados obtidos por meio da aplicação e posterior análise dos questionários realizados na área de estudo durante as quatro etapas da pesquisa demonstraram o perfil do usuário do Jardim Botânico de Curitiba, conforme ilustra a tabela 1. 
TABELA 1 - PERFIL DO USUÁRIO DO JARDIM BOTANICO DE CURITIBA

\begin{tabular}{|c|c|c|c|}
\hline \multirow{2}{*}{$\begin{array}{l}\text { Variável } \\
\text { Gênero }\end{array}$} & \multirow[b]{2}{*}{$\begin{array}{l}\text { Masculino } \\
\text { Feminino }\end{array}$} & \multicolumn{2}{|c|}{ Quantidade Porcentagem } \\
\hline & & $\begin{array}{l}461 \\
524\end{array}$ & $\begin{array}{l}47 \% \\
53 \%\end{array}$ \\
\hline \multirow[t]{5}{*}{ Faixa etária } & Até 18 anos & 146 & $15 \%$ \\
\hline & De 19 a 30 anos & 304 & $31 \%$ \\
\hline & De 31 a 45 anos & 224 & $23 \%$ \\
\hline & De 46 a 60 anos & 160 & $16 \%$ \\
\hline & Acima de 60 & 151 & $15 \%$ \\
\hline \multirow[t]{4}{*}{ Escolaridade } & Ensino fundamental & 217 & $22 \%$ \\
\hline & Ensino médio & 306 & $31 \%$ \\
\hline & Graduação & 258 & $26 \%$ \\
\hline & Pós-graduação & 204 & $21 \%$ \\
\hline \multirow[t]{5}{*}{ Origem } & Curitiba & 367 & $37 \%$ \\
\hline & $\begin{array}{l}\text { Região Metropolitana } \\
\text { Outra cidade do Estado }\end{array}$ & 47 & $5 \%$ \\
\hline & do Paraná & 155 & $16 \%$ \\
\hline & Outro Estado & 381 & $39 \%$ \\
\hline & Outro País & 35 & $3 \%$ \\
\hline
\end{tabular}

Fonte: A autora (2012)

Do total de 985 entrevistados desta pesquisa $53 \%$ eram mulheres e $47 \%$ homens. A faixa etária predominante, com $31 \%$ das respostas, foi a de 19 a 30 anos, seguida da faixa etária de 31 a 45 anos com 23\%. O nível de escolaridade mais representativo foi o ensino médio, com $31 \%$, seguido da graduação, com $26 \%$ das respostas obtidas.

Identificou-se que na origem do usuário do atrativo em estudo destacam-se o residente da cidade de Curitiba, e os residentes de outros estados, os quais representaram $37 \%$ e $39 \%$ das respostas, respectivamente.

Os dados de origem do usuário do Jardim Botânico de Curitiba encontrados nesta pesquisa coincidem com os resultados apresentados no relatório de demanda turística elaborado pelo Instituto Municipal de Turismo local (CURITIBA, 2009) e com pesquisas acadêmicas, com o tema turismo em áreas verdes de Curitiba, desenvolvidas por Kaick et al. (2006), e Ribeiro e Silveira (2006). 


\subsection{FATOR MOTIVACIONAL À VISITAÇÃO AO JARDIM BOTÂNICO DE CURITIBA}

Em relação à motivação de visita ao atrativo em estudo, de acordo com as respostas obtidas, juntos aos 985 usuários questionados durante as quatro estações do ano, as opções lazer e turismo destacaram-se com 44\% e 42\% das respostas, respectivamente, sendo $14 \%$ das afirmações enquadradas na opção outros (TABELA 2).

\section{TABELA 2 - FATOR MOTIVACIONAL À VISITAÇÃO AO JARDIM BOTÂNICO DE CURITIBA}

\begin{tabular}{l|c|c}
\hline Fator motivacional & Quantidade & Percentagem \\
\hline Lazer & 433 & $44 \%$ \\
Turismo & 414 & $42 \%$ \\
Outros & 138 & $14 \%$ \\
Total & 985 & $100 \%$
\end{tabular}

Fonte: A autora (2012)

De acordo com dados da Curitiba Turismo, a motivação de viagem no ano de 2009 dividiu-se entre negócios 38\%; visita a amigos e familiares $22 \%$ e lazer $22 \%$ (CURITIBA, 2009). Cabe ressaltar que a cidade recebeu premiação do Ministério do Turismo de melhor prática no quesito monitoramento da demanda turística (BRASIL, 2010)

Em âmbito nacional, segundo dados do Ministério do Turismo, 46\% os turistas que visitaram o país, no ano de 2010, declaram ser o principal motivo da viagem o lazer; $23 \%$ eventos e $31 \%$ outros (BRASIL, 2010).

Estes resultados corroboram a afirmação de Andrade (2006), segundo o qual a necessidade que os indivíduos possuem de troca de ambiente físico e de evasão é uma das motivações que impulsionam as pessoas à prática do lazer e do turismo.

Nesta pesquisa os residentes da cidade de Curitiba, 37\%, e da região metropolitana, $5 \%$, foram os que afirmaram ser o lazer o motivo da visita ao Jardim Botânico de Curitiba, este resultado coincide com o estudo realizado por Hildebrand et al. (2002) no Bosque Alemão de Curitiba, no qual os entrevistados também 
apontaram as áreas verdes como os principais locais escolhidos para a prática de lazer aos finais de semana.

Observou-se que os usuários provenientes de outras cidades do Paraná, de outros estados e outros países, todos estes inclusos na categoria turista (BENI, 2004), não tiveram como motivação de visita ao Jardim Botânico de Curitiba o lazer, mas sim o turismo.

Durante as quatro estações do ano as motivações de visita ao Jardim Botânico de Curitiba não apresentaram variações, contudo, Silva (2012) concluiu em sua pesquisa que o clima da cidade de Curitiba é um atrativo local que pode também ser considerado um fator de motivação de viagem.

A localização do município de Curitiba em relação ao Trópico de Capricórnio, a topografia do primeiro planalto e a barreira geográfica natural da Serra do Mar são os fatores que corroboram para a existência de um clima peculiar e paisagens exuberantes (IPPUC, 2011).

Estudos realizados em outros Jardins Botânicos brasileiros apontam o lazer como principal fator motivacional de visita, sempre aliado a outros fatores que contribuem para uma experiência de visitação agradável nestes ambientes. A utilização destes espaços pela comunidade local e regional também é destaque nos resultados encontrados por alguns autores.

Reis (2001) em seu estudo sobre as formas de utilização e os determinantes ambientais para a prática de atividades físicas no Jardim Botânico de Curitiba e seus resultados demonstraram que os usuários são predominantemente adultos, residentes próximos ao local de estudo, de ambos os sexos, com elevado nível socioeconômico e prática de atividades físicas acentuada, encontrou ainda que a beleza do local estimulam a prática de atividades físicas e que as condições climáticas inibem a realização destas atividades.

Vitaliano et al. (2006) no projeto de pesquisa realizado no Jardim de Botânico do Instituto de Biociências de Botucatu, ligado a Universidade Estadual Paulista, identificou que o espaço é utilizado pela comunidade regional, sendo as motivações de visita o conhecimento por meio de informações sobre o local e a prática do lazer.

Firmino (2009) em seu estudo de viabilidade de um roteiro turístico ambiental cultural na cidade de São Paulo identificou como motivação de visita ao 
horto florestal, área similar a um jardim botânico, o lazer com $51 \%$ do total de respostas, sendo que $26 \%$ dos entrevistados residem próximo ao local de estudo e $24 \%$ residem a uma distância curta a média entre 10 a 15 km.

Mendonça et al. (2012) em pesquisa sobre os motivos que levaram as pessoas visitarem o Jardim Botânico da Fundação Zoo-Botânica de Belo Horizonte, Minas Gerais, 67,13\% dos entrevistados assinalaram mais de uma opção, dentre as listadas no questionário, tais como a prática do lazer, a prática de atividade física, o contato com a natureza e a compra de mudas de plantas. Esta diversidade de motivações demonstrou a importância atribuída ao local e a percepção dos diversos benefícios oferecidos aos visitantes, sendo que 46,05\% destes são residentes de Belo Horizonte e $46,67 \%$ de outras cidades do Estado.

Em relação a estudos internacionais referentes a fatores motivacionais à visitação de Jardins Botânicos em Brisbane, Queensland, Ballantyne et al. (2008) identificaram que nos Jardins Botânicos desta região da Austrália a admiração da paisagem, a prática de atividades de lazer destacando a importância de passar tempo com amigos e familiares em um ambiente natural são os principais fatores de visita. A procedência geográfica majoritária dos entrevistados foi local, sendo $73 \%$ destes residentes de Brisbane e 10\% proveniente de outras partes de Queensland.

Ward et al. (2010) constataram nos seis Jardins Botânicos da África do Sul, o contentamento em desfrutar a beleza natural, a combinação de diversos outros fatores, os quais tem o lazer como resultado final e a prática de exercícios físicos, como os principais fatores motivacionais á visitação. O público entrevistado também em sua maioria foi composto por residente do entorno dos Jardins Botânicos estudados, totalizando $73 \%$ do total.

Observa-se em âmbito nacional e internacional que o fator motivacional denominado lazer está estreitamente relacionado com o uso público destas áreas por residentes locais e do entorno geográfico, além dos turistas provenientes de outras regiões e países.

Connell (2004) também argumenta que a visitação aos Jardins é uma forma de turismo cultural e aponta uma diversidade de motivações que levam os indivíduos a visitarem estes espaços, desde o desejo de admirar exposições de plantas, ou o trabalho de arquitetos da paisagem ou designers de jardins, até as mais simples motivações, como se refugiar em dias quentes, respirar ar puro em um ambiente 
agradável ou até mesmo dispensar um dia inteiro apenas para apreciação destes espaços.

Contudo, apesar da quantidade limitada de estudos sobre Jardins Botânicos, nacionais e internacionais (CONNELL, 2004), os resultados encontrados e aqui discutidos demonstram a importância destas áreas verdes para a sociedade contemporânea.

\section{CONCLUSÕES}

As características predominantes dos usuários do Jardim Botânico de Curitiba encontradas nesta pesquisa foram: gênero feminino; faixa etária de 19 a 30 anos; nível médio de escolaridade; origem geográfica de outro estado; e motivação de viagem o lazer.

Reconhecendo o lazer como principal motivo de visitação ao Jardim Botânico de Curitiba é importante ressaltar a existência de uma programação diferenciada e atrativa que se estende desde exposições artísticas e botânicas até a sensibilização ao uso dos sentidos, poucos explorados na apreciação da natureza, tais como olfato e tato, no Jardim das Sensações.

A infraestrutura receptiva do Jardim Botânico de Curitiba é refletida nos resultados de pesquisa de demanda (CURITIBA, 2009) que apontam este atrativo como o mais visitado da cidade.

Observa-se que a prática do lazer e do turismo são atividades correlatas que apresentam crescimento em âmbito nacional e internacional em um contexto de resposta aos anseios da população urbana do presente século em estar em contato com a natureza em espaços de lazer que proporcionem um escape ao estresse diário e qualidade de vida.

Diante da escassez de estudos relacionados à motivação de visita a jardins botânicos e áreas verdes em geral, este trabalho coloca em evidência os pontos positivos do Jardim Botânico de Curitiba, os quais podem ser utilizados como modelo a outras áreas verdes e similares.

A temática motivação de visita às áreas verdes possui, portanto, um amplo campo de pesquisa, cujos resultados podem transformar-se em ferramentas de gestão direcionada ao atendimento das expectativas do usuário, bem como incentivo 
à promoção do uso destas áreas, seja por integrantes da população local ou por turistas.

Neste sentido, esta pesquisa identificou que independente das estações do ano a origem geográfica dos usuários da área de estudo, foi o fator determinante para estabelecer o lazer como principal motivador de visitação, pois os residentes da cidade de Curitiba são os que mais utilizam o Jardim Botânico, com finalidade de lazer, enquanto que os usuários do atrativo provenientes de outras localidades afirmaram ser o turismo a motivação da visita.

Desta forma, o resultado encontrado nesta pesquisa é um reflexo da segmentação da atividade turística com destaque para as atividades de lazer e turismo na cidade de Curitiba, em concordância com as motivações de viagens nacionais e internacionais.

\section{REFERÊNCIAS}

ANDRADE, J. V. Turismo Fundamentos e Dimensões. 8. ed. São Paulo: Ática, 2006.

BALLANTYNE, R.; HUGHES, K. Environmental awareness, interests and motives of botanic gardens visitors: implications for interpretative practice. Tourism Management, v. 29, n. 3, p. 439-444, 2008.

BENI, M. C. Análise estrutural do turismo. 10. ed. São Paulo: Senac São Paulo, 2004.

BRASIL. Constituição da República Federativa do Brasil, 1988. Disponível em:<http://www.planalto.gov.br/ccivil_03/constituicao/constitui\%C3\%A7ao.htm> Acesso em: 20/12/2011.

BRASIL. Dados do Turismo Brasileiro. Ministério do Turismo, 2010. Disponível em: <http://www.turismo.gov.br/dadosefatos/> Acesso em 04/04/12.

BRASIL. Lei $\mathrm{n}^{\circ}$ 6.938, de 17 de janeiro de 1981. Dispõe sobre a Política Nacional do Meio Ambiente, seus fins e mecanismos de formulação e aplicação, e dá outras providências.

Disponível em: <http://www.planalto.gov.br/ccivil_03/leis/L6938.htm>. Acesso em: 20/12/2011.

BRASIL. Lei $\mathbf{n}^{\circ}$ 9.985, de 18 de julho de 2000. Regulamenta o art. 225, $\S 1^{\circ}$, incisos I, II, III e VII da Constituição Federal, institui o Sistema Nacional de Unidades de 
Conservação da Natureza e dá outras providências. Disponível em:<http://www.planalto.gov.br/ccivil_03/leis/L9985.htm>. Acesso em: 20/12/2011.

BRASIL. Melhor prática vencedora: monitoramento (capital). Demanda Turística de Curitiba - Estudo do perfil, comportamento e opinião dos turistas que visitam a capital paranaense, inclusive em eventos geradores de fluxo turístico. Ministério do Turismo. Disponível em: <http://www.turismo.gov.br/export/sites/default/turismo/noticias/acontece/download_a contece/Curitiba_Monitoramento_RELATO_DA_MELHOR_PRxTICA.pdf> Acesso em 04/ 04/12.

BRASIL. Resolução Conama n $^{\circ} 266$ de 03 de agosto de 2000 . Estabelece diretrizes para a criação de jardins botânicos. Disponível em: <http://www.jbrj.gov.br/cnjb/INSTRU.pdf>. Acesso em: 20/12/2011.

BRASIL. Resolução Conama $n^{\circ} 287$ de 30 de agosto de 2001. Complementa a resolução 266 de 03 de agosto de 2000. Disponível em: <http://www.jbrj.gov.br/cnjb/INSTRU.pdf>. Acesso em: 20/12/2011.

CONNELL, J. The purest of human pleasures: the characteristics and motivations of garden visitors in Great Britain. Tourism Management, n. 25, v. 19, p. 229-247, 2004.

CURITIBA. Instituto Municipal de Turismo. Pesquisa de demanda turística, perfil e opinião. Curitiba, 2009.

FIRMINO, G. Turismo ambiental responsável em áreas urbanas é possível? 0 estudo de viabilidade de um roteiro turístico ambiental-cultural na cidade de São Paulo. 101f. Monografia. (Bacharelado em Turismo). UNESP, Rosana, 2009.

HARDT, L. P. Subsídios à gestão da qualidade da paisagem urbana: aplicação à Curitiba - Paraná. 323 f. Tese (Doutorado em Engenharia Florestal). Setor de Ciências Agrárias, UFPR, Curitiba, 2000.

HILDEBRAND, E.; GRAÇA, L. R.; HOEFLICH, V. A. "Valoração Contigente" na avaliação econômica de áreas verdes urbanas. Floresta, v. 32, n. 1, p. 121-132, 2002.

INSTITUTO DE PESQUISA E PLANEJAMENTO URBANO DE CURITIBA (IPPUC). Estatística - Demanda Turística de Curitiba, 2007. Disponível em: $<$ http://www.ippuc.org.br/.../Curitiba_em_dados_Pesquisa.asp >. Acesso em: 31/05/ 2010.

LIMA, A. M. L. P.; CAVAlHEIRO, F.; NUCCI, J. C.; SOUZA, M. A. L. B.; FIALHO, N. O; DEL PICCHIA, P. C. D. Problemas de utilização na Conceituação de termos como espaços livres, áreas verdes e correlatos. In: Congresso Brasileiro sobre Arborização Urbana, II, São Luiz/MA, 18-24/09/94. Anais. p. 539-550. 
MACEDO, S. S.; SAKATA, F. G. Parques Urbanos no Brasil. Brazilian Urban Parks. 3. ed. São Paulo: Editora da Universidade de São Paulo, 2010.

MENDONÇA, M. P.; WINDHAM - BELLORD, K. A.; ANDRADE, D. C.; RESENDE, F. M.; VERÍSSIMO, M.P. Valoração Econômica do Jardim Botânico da Fundação Zoo-Botânica de Belo Horizonte, Minas Gerais.

Disponível em:

<http://www.ie.ufu.br/sites/ie.ufu.br/files/Anexos/Bookpage/Relat\%C3\%B3rioJardimB ot\%C3\%A2nicoFZB-BH-Final_0.pdf> Acesso em: 11/07/2012.

PEREIRA, T. S.; COSTA, M. L. M. N. Os Jardins Botânicos brasileiros: desafios e potencialidades. Ciência e Cultura, v. 62, n. 1, p. 23-25, 2010.

REDE BRASILEIRA DE JARDINS BOTÂNICOS (RBJB). Jardim Botânico Municipal FMGR. Diversidade biológica nos jardins botânicos brasileiros. Rio de Janeiro, 2004.

REIS, R. S. Determinantes ambientais para a realização de atividades físicas nos parques urbanos de Curitiba: uma abordagem sócio-ecológica da percepção dos usuários. $114 \mathrm{f}$. Dissertação (Mestrado em Educação Física). Centro de Desportos, UFSC, Florianópolis, 2001.

SEGAWA, H. Ao amor do público: jardins no Brasil. São Paulo: Studio Nobel FAPESP, 1996.

SILVA, R. R. S. Avaliação paisagística e turística do Jardim Botânico de Curitiba, Paraná, Brasil.106 f. Dissertação (Mestrado em Engenharia Florestal). Setor de Ciências Agrárias, UFPR, Curitiba, 2012.

SILVA, R. R. S. Avaliação dos equipamentos e serviços turísticos do Jardim Botânico, Curitiba, Paraná, (Brasil). Turismo em Análise, v. 23, n. 1, p. 187-206, 2012.

URBS - URBANIZAÇÃO DE CURITIBA. Linha turismo. Disponível em: <http://www.urbs.curitiba.pr.gov.br/PORTAL/linha_turismo/>. Acesso em: 23/03/2012.

VITALIANO, F.; VAZ, G. L.; DELACHIEVE, M. E. A.; ALMEIDA, L. F. R. Preservação ambiental como instrumento de cidadania: Jardim Botânico e Sociedade. Revista Ciência em Extensão, v. 2, suplemento, p. 34, 2006.

WARD, C.; PARKER, C. M.; SHACKLETON, C. M. The use and appreciation of botanical gardens as urban green spaces in South Africa. Urban Forestry \& Urban Greening, v. 9, n. 1, p. 49-55, 2010. 


\section{APÊNDICE 1}

\section{MODELO QUESTIONÁRIO}

\section{UNIVERSIDADE FEDERAL DO PARANÁ \\ PROGRAMA DE PÓS-GRADUAÇÃO EM ENGENHARIA FLORESTAL AVALIAÇÃO TURISMO}

Local da coleta

Data

Dia da semana

Clima

\begin{tabular}{|c|c|}
\hline Gênero: & ( ) Masculino \\
\hline Qual sua faixa etária? & $\begin{array}{ll}\text { ( ) até } 18 \text { anos } & \text { ( ) de } 19 \text { a } 30 \text { anos } \\
\text { ( ) de } 31 \text { a } 45 & \text { ( ) de } 46 \text { a } 60 \text { anos } \\
\text { ( ) acima de } 60 & \end{array}$ \\
\hline $\begin{array}{l}\text { Qual seu grau de } \\
\text { escolaridade? }\end{array}$ & $\begin{array}{ll}\text { ( ) } 1^{\circ} \text { grau } & \left(\text { ) } 2^{\circ} \text { grau }\right. \\
\text { ( ) graduação } & \text { ( ) pós-graduação }\end{array}$ \\
\hline $\begin{array}{l}\text { Qual a região de sua } \\
\text { residência? }\end{array}$ & $\begin{array}{l}\text { ( ) Curitiba } \\
\text { ( ) Região Metropolitana de Curitiba } \\
\text { ( ) Outra cidade do estado do Paraná } \\
\text { ( ) Outro estado ( ) Outro país }\end{array}$ \\
\hline $\begin{array}{l}\text { Qual o motivo da sua } \\
\text { visita ao Jardim Botânico de } \\
\text { Curitiba? }\end{array}$ & $\begin{array}{l}\text { ( ) Lazer ( ) Turismo ( ) Pesquisa } \\
\text { ( ) Outros }\end{array}$ \\
\hline
\end{tabular}

(Recebido em: 19/05/2012. Aceito em 22/08/2012). 